\title{
THE IMPACT OF SEX EDUCATION ON TEENAGE PREGNANCY IN BASIC SCHOOLS OF BAWKU MUNICIPAL DISTRICT IN GHANA
}

\author{
Anthony Kudjo Donkor* and Azure Love Lariba \\ Faculty of Education, University for Development Studies, Tamale, Ghana \\ *corresponding e-mail: akudjod@yahoo.com
}

\begin{abstract}
The incidence of teenage pregnancy has been on the rise in Ghana, especially in the Bawku-East Municipality. In Ghana adults rarely discussed sexual matters with the youth. Thus, the youth have little or no information about the biological changes that take place in their bodies during the transitional period from youth to adulthood. This has resulted in unplanned pregnancies for the vast majority of teenagers, which have serious developmental and socioeconomic implications. The study was to explore how sex education could mitigate teenage pregnancy in the Bawku-East Municipality. A total sample size of one hundred and thirty-nine (139) respondents was used for the study. Questionnaires, in-depth interviews, focus group discussions and observation were used to collect data for the study. The study revealed that poor parenting, poverty and peer influence were the major causes of teenage pregnancy in the study area. In addition, concealing sex education and sex-knowledge from the youth made them more curious and vulnerable. There is the need for parents and schools to empower the youth through sex education to equip them with knowledge in order to overcome the potentially corrupt information through the social media and friends. The study will be useful to students, parents, teachers and vulnerable group (girl-child) advocates in communities.
\end{abstract}

Keywords: Basic schools, Ghana, sex education, teenage pregnancy, teenagers

(C) 2017 Department of Biology Education, FTTE, University of Muhammadiyah Malang, Indonesia

\section{INTRODUCTION}

Education is regarded as an important tool for the development of an individual, the community and the nation at large. For this reason, nations all over the world are concerned with the provision of education to their citizens. Many African countries see development as closely intertwined with education; that the more educated their citizens are the higher their ability to deal with the problems of development (World Bank, 2005)It is in the light of this and other factors that countries all over the world are making frantic efforts at reducing the number of out-of-school children (Wikan, n.d.). Basic education provides the essential building blocks for higher levels of education. It also lays the foundation upon which work-related skills are developed, especially for those who are not able to continue to the higher levels of the academic ladder.

The government of Ghana introduced the Free-Compulsory Universal Basic Education in 1996 with the aim of providing quality education to all children. In view of the compulsory nature of basic education in Ghana, the government and agencies have made concerted efforts to address educational inequality and improve quality. The government introduced the capitation grant scheme to defray school fees previously charged. The school feeding programme was introduced in some selected schools in deprived communities. All these measures were put in place to cushion the burden of parents in meeting the cost of sending their children to school and to encourage parents especially in deprived areas to send their children to school (MoE, 2013; UNICEF, 2007b).

The benefits of educational attainment to future opportunities for the individual, community and society have some impediments such as school dropouts, especially that of the female students. According to Nakanyike et al. (2002), 115 million school going-age children are out of school. This number is equivalent to $18 \%$ or almost one in every five of the children in the school going age group worldwide. In addition, data from Ghana Demographic and 
Health Survey and Multiple Indicator Cluster Survey through the World Inequality Database on Education (WIDE, 2014) out of school JHS pupils stood at 53\% for males and 54\% for females. The causes of dropout were attributed to parental ignorance of the importance of education, poverty, and other issues such as teenage pregnancy (WIDE, 2014).

The research focused on teenage pregnancy as one of the causes of school dropout, in the Bawku East District and evaluated the impact of sex education on pupils' of basic schools to reduce the high rates of teenage pregnancies in the District. Sex education is based on the instruction on issues relating to human sexuality such as human sexual anatomy, sexual reproduction system, sexual intercourse, reproductive health, emotional relations, reproductive rights and responsibilities. In addition, it includes abstinence, birth control, contraception, sexually transmitted diseases, and other aspects of human sexual behaviour. Common avenues for sex education are parents or caregivers, formal school programmes, and public health campaigns. For any sex education to be successful especially in Africa, the culture of the immediate recipients must be put into consideration when selecting content and methodology. It is believed that human sexuality has biological, physical, emotional and spiritual aspects. The biological aspect of sexuality refers to the reproductive mechanism as well as the basic biological drive, libido that exist in all species, which is strongly influenced by hormonal levels. The emotional or physical aspect of sexuality refers to the bond that arises between individuals, and it is manifested physically or emotionally through love, trust and care. There is also a spiritual aspect of sexuality of an individual or a connection with others. Experience has shown that adolescents are curious about aspects of their sexuality as well as the nature of sexuality in general, and that many will seek to experience their sexuality in some way.

Traditionally, adolescents in many cultures were not given any information on sexual matters, because such discussions were considered a taboo. Such instructions were left to a child's parents, and often this was put off until just before marriage (Osei, 2009; Owusu, 2012). As part of the effort to reduce teenage pregnancies, programmes of sex education were instituted by some countries initially over strong opposition from parents and religious groups. Moreover, the outbreak of AIDS has given a new sense of urgency to sex education as a strategy for risk control.

Historically, teenage pregnancy in Ghana was not seen as a problem at all, as most girls married soon after puberty, and puberty typically occurred at a later age than it does now. In addition, young people who wish to finish secondary school were likely to be sexually mature before marrying. However, the trend has seen a significant change. For example, globally, 16 million girls at age 15 to 19 years and 12 million girls under the age of 15 give birth every year. According to WHO's report one (1) in five (5) girls give birth by the age of 18 (WHO, 2014).

Pregnancy among teenagers in Ghana is a significant problem, and may actually be increasing. Annually an estimated number of 750,000 teenagers between ages of 15 to 19 years become pregnant in Ghana with the Upper East region recording about 14,000 in 2012 (GNA, 2013a; GNA, 2013b). The Upper East Region of Ghana is steadily experiencing an increase in teenage pregnancies with teens engaging in premarital sexual activities. According to the Upper East Regional Director of Health Services, vital statistical reports showed that in 2006, out of the 40,949 pregnancies that were registered in anti-natal facilities, 6,866 were teenagers representing $16.8 \%$ (Awoonor, 2010).

In order to address the issue above it is expedient to look at examples from other countries that have successfully minimized this problem. At 2.9 births per 1000 teenaged women, South Korea has the lowest teen pregnancy rate in the world. Also in the top 5 is the Netherlands, with 6.2 births per 1000 (UNICEF, 2007a). Because of vastly different cultural and economic contexts, it is not possible to find one set of policy that works in every country. South Korea's low teen pregnancy rates apparently are mostly due to a set of traditional values about sexuality that has not yet been eroded by modern life (UNICEF, 2007a). Young people are always kept busy, closely supervised and controlled by their parents and other authority figures. While discussions on sex issues continue to be regarded as a taboo and sex education in schools remain limited in Ghana, the Netherlands, attitudes towards sexuality are very liberal and open, and sex education is well-established in the school curriculum. Sex 
education starts before children are old enough to be embarrassed by the subject. There is adequate information on effective birth control as well (UNICEF, 2007a).

The intolerance for sex education and sexual encounters among the youth of Ghana are becoming increasingly alarming. These lead to unwanted pregnancies, prolific infections and massive drop-out rates from schools. The risk of attracting HIV virus is very high among the youth. Girls are worst affected with early pregnancies cutting short their dreams to continue their education. In the absence of a cure or vaccine for teenage pregnancy or HIV/AIDS, educating children about safe sex is regarded by many as the primary means for prevention. The United Nations and others have described it as "the social vaccine" but the question of how best to do this has long been debated. The need for such efforts remain acute but it is fraught with difficulty as deep-rooted socio-cultural, religious and moral constraints remain barriers to effective sex education across Africa (Secura et al., 2014). It is anticipated that this study will be useful to students, parents, educationists and health authorities in their effort to fight the social menace of teenage pregnancy in Ghana and beyond.

Four main themes were discussed in the study to reduce teenage pregnancies in the Bawku Municipal District of Ghana. They include, prevalence and trends of teenage pregnancy in the District; participants' perceptions of teenage pregnancy and the implications; causes of teenage pregnancy; contents, quality and delivery methods of sex education curricula and impact on teenage pregnancy.

\section{METHOD}

\section{The Study Area}

Bawku Municipal is one of the thirteen (13) Districts and municipalities in the Upper East Region of Ghana. The municipality has a total land area of about $12.1505 \mathrm{~km}^{2}$. It shares boundaries with Burkina Faso, Togo, Bawku West and Garu-Tempane District to the north, east, west and the south respectively. The administrative capital is Bawku (Bawku Municipal District, 2017). In 2012, Bawku had a settlement population of 69,527 people. The Kusasis (Kusaal) are the indigenous inhabitant population of the Bawku area. There are however large immigrant populations from other locations in northern and southern Ghana as well as from Burkina Faso, Ivory Coast, Togo, and Nigeria. The District is characterized by agriculture. It is made up of the following constituencies: Bawku Central, Binduri, and Pusiga (Bawku Municipal District, 2017).

\section{Population of the Study}

The District is divided into four (4) educational circuits namely, Urban Circuit A, B, C, and D with 22 Junior High Schools (JHS), Zabugu Circuit- 2 JHS, Kuka Circuit- 4 JHS and Mognori Circuit- 6 JHS. In addition to the public schools in the study were 2 private JHS in the municipal out of 11 . There were 34 Junior High Public Schools in the municipality with 11 privately owned schools having a total enrolment of 10,285 pupils. The total number of JHS was 34 with an enrolment of 3,321 pupils. The District had a total number of 658 teachers.

\section{Sample and Sampling Procedure}

Three sampling methods were used in the selection of participants for the study. These include the snowball, purposive and simple random sampling methods. Teacher and pupil respondents were selected through the simple random sampling method. This method was used because every school had experienced one form of teenage pregnancy or another, so it was imperative that every head teacher and teacher was in a position to give useful information to the study. Total sample size of 139 respondents was used for the study. There were 125 pupils used for the study. In view of this, all teachers and head teachers in the municipality were grouped and 7 teachers with 7 head teachers were accordingly selected. The register that contained the names of teachers in the municipality was obtained and one by one the names were written on pieces of paper. The papers with the names were placed in a bowl. With the help of the research assistants, the lottery method was used to select 14 schools. A total of 125 pupils were selected from the four (4) circuits in the municipality.

\section{Instruments for Collecting Data}

Semi-structured interview, questionnaires, and observation were employed as a result of the sensitive nature of the research. It was anticipated that unexpected answers and information may be discovered in interview, hence this type of interview in order to 
supplement the frequency between the identified variables and hypothesis.

Secondary data collection and literature review (document study) were also employed as instruments for the research. The available datasets such as surveillance data, needs assessment data, and epidemiological profiles of national and local incidence were resorted to. Prevalence trends provided the information necessary to profile the extent of the burden and disparity of sex education by detailing trends in causes and consequences of teenage pregnancy.

\section{Data Collection Procedure}

In order to ensure that data collection was smooth, five research assistants were hired from among teachers in the various circuits. The research assistants were briefed on the objectives of the study and were coached on how to interview respondents for the study. The selection of the research assistants was informed by the local conditions and the background knowledge of the teacher in a particular circuit. Each research assistant was assigned to one circuit to interview teenage girls. Teachers and head teachers were interviewed by the researchers. Before the advent of field interviews the researchers visited the District Education Office to seek permission from the Municipal Director of Education. Consequently, the Director gave all the needed assistance in terms of the number of teachers and head teachers in the District. It was from the two lists that teachers and head teachers were selected for the interview. Data collection with respect to health workers and school dropouts as a result of teen pregnancy were facilitated by teachers and head teachers. The needed support was given to the research assistants in identifying the teenage dropouts.

\section{Data Analysis Procedure}

Methods of data analysis using qualitative descriptive research paradigm, supported by quantitative data based on theories related to keyword of research. Data collected was edited for clarity of expression, and information was broken down into meaningful sentences. Similar responses were grouped taking into account the objectives of the study. The data obtained were processed with descriptive techniques. Some of the results were put into tables. The selected data were analysed using percentages. Frequency tables were also used to enhance the presentation of the data.

\section{Limitations}

The main challenge was the unwillingness of pregnant teenagers or teenage mothers to participate in the study. Most of the pregnant teenagers were shy to participate so much time was spent to explain the purpose of the study as well as to assure them of the confidentiality of their responses (input).

\section{RESULTS AND DISCUSSION}

The study was on sex education as a means to curb teenage pregnancies in basic schools of the Bawku Municipal District in the Upper East Region of Ghana. A total of 125 pupils were selected from the 4 circuits in the municipality. In order to have a deep insight into the rate of pregnancy and the teaching of sex education, 7 head teachers and 7 classroom teachers were interviewed to solicit their input. In all 99\% of the participants took part in the study. The presentation of results was done according to sections dedicated to each of the four specific objectives that guided the study.

\section{Background Characteristics of Pupils}

The background characteristics of pupils were considered relevant to the study. These include, age distribution, class at which they became pregnant and reported pregnancy cases in the area of the study. These are presented in Table 1, Table 2 and Table 3.

Table 1. Age of respondents

\begin{tabular}{ccc}
\hline Age & $\begin{array}{c}\text { Number of } \\
\text { respondents }\end{array}$ & $\begin{array}{c}\text { Percent } \\
\text { respondents }\end{array}$ \\
\hline 13 & 6 & 4.8 \\
14 & 14 & 11.2 \\
15 & 25 & 20.0 \\
16 & 27 & 21.6 \\
17 & 28 & 22.4 \\
18 & 17 & 13.6 \\
19 & 8 & 6.4 \\
\hline Total & 125 & 100 \\
\hline
\end{tabular}

(Source: Field data, 2017)

From Table 1, the age distribution of pupils was displayed. The study captured all teen ages with most of the respondents falling within15, 16 and 17 years category and $20.0 \%, 21.6 \%$ and $22.4 \%$ respectively whereas the least age category being those who were 13,14, 18 and 19 years and $4.8 \%, 11.2 \%, 13.6$ and $6.4 \%$ respectively. The ages were of critical importance in the research because the focus was on teenage learners (13-19), and it was of 
importance to establish the age of the respondent before the interview took place. It is also the stage where biological changes begin to take place in the body.

The Ghanaian youth today are entering into sexual relationships early; because at the teen age they are sexually active (GNA, 2008). Some even start having sexual intercourse at much younger ages that is between 9 and 18 years (Ansah-Addo, 2005). There is the emerging trend of increased sexuality among the youth and their vulnerabilities (child sexual abuse, teenage pregnancy, STDs) as well as the other complications that come with promiscuity and pre-marital sex (Schwartz \& Rutter, 1998).

The second background characteristic that was of concern to the researchers was the levels at which pupils were in school. Table 2 shows that $51.2 \%$ of the pupils were at form one (1) level, whilst $48.8 \%$ of the pupil were at the form two (2) level of JHS.

Table 2. Class/Level

\begin{tabular}{ccc}
\hline Class & $\begin{array}{c}\text { Number of } \\
\text { respondents }\end{array}$ & $\begin{array}{c}\text { Percent } \\
\text { respondents }\end{array}$ \\
\hline Form one & 64 & 51.2 \\
Form two & 61 & 48.8 \\
\hline Total & 125 & 100 \\
\hline
\end{tabular}

(Source: Field data, 2017)

It was noted that the level at which a pupil became pregnant at school was not an independent factor; rather, it was dependent on factors such as weak family support, poor academic performance, childhood environment and low education value (Sottie \& Awasu, 2011).

\section{Theme One: Prevalence and trend of teenage pregnancy in the District}

This theme sought to find out some of the prevalence and trends of teenage pregnancy in the study area. The study revealed that, 122 respondents $(97.6 \%)$ affirmed their friends or mates ever became pregnant. However, 3 respondents $(2.4 \%)$ said they never heard or observed any of their friends or mates became pregnant. The study also sought to find out, how often their friends or mates became pregnant: 118 respondents $(94.4 \%)$ said their friends or mates got pregnant most often, 4 respondents $(3.2 \%)$ said their friends or mates seldom became pregnant, and 3 respondents $(2.4 \%)$ said they did not know how often their friends or mates became pregnant.
Perceptions on the rate of pregnancies revealed that 92 respondents $(73.6 \%)$ agreed that, the rate of pregnancy was high in their respective schools. Nonetheless, 30 respondents (24\%) perceived that the rate of pregnancies in their respective schools was low. Only 3 respondents $(2.4 \%)$ acknowledged that they never observed any of their mates or friends becoming pregnant and so were not able to determine the rate of pregnancies in their respective schools. The researchers asked why those 3 respondents were exceptions to the other respondents and they said that they were transferred students from other schools.

\section{Theme Two: Participants' perceptions of teenage pregnancy and the implications}

Most teachers were uninformed when it comes to the handling of problems that were related to sex and sexuality. There was a serious need to train teachers on this issue as it appears most of them still hold conservative attitude towards sex. In schools pupils only learn about their body organs and their physiological functions such as the reproductive system and sex organs. Pupils have limited knowledge in sex education that results into unplanned pregnancy which in turn disrupted progress at school. It was believed that health institutions such as clinics and hospitals sometimes indirectly compound problems. They provided preventive measures such as pills or condoms to young girls between the ages of twelve and sixteen dubbed "family planning". Teenage girls leave the clinics and hospitals with the wrong perception that they have the potential of planning their families and they get trapped in the web of teenage pregnancy (Boult \& Cunningham, 1996).

\section{Theme Three: The causes of teenage pregnancy}

Many factors have been found as the main causes of teenage pregnancy. Among these factors are poor parenting, parent-teenage relationship, peer pressure influence, uncontrolled sex feelings, sexual abuse, socioeconomic factors and childhood environment. The study revealed that $73.6 \%$ of the pupils lived with their biological parents; while $26.4 \%$ of the pupils were under the care of their grandparents or relatives while their parents worked elsewhere. Parenting skills and parental attitudes have great implications on the lives and attitudes of children. It is often argued that 
domestic violence and lack of love from parents for their wards most often forced teenage girls to seek for that love from their colleague males, which may result in early sex and the associated vice such as teenage pregnancy. Parents' inability to make time to discuss serious life issues with their children paved way for teenage pregnancy. It is naïve for a parent to withhold information about sex and sexuality from their children whilst such information can easily be obtained from the media and friends. It is often unknown to some parents that the teen years are the years of great adjustment and they are when communication is mostly needed, but instead this is the time when communication is at its lowest level between parents and their children. This is because parents think that children know nothing about sex whereas they know everything except its dangers, such as contraction of sexually transmitted diseases (STD's) and pregnancy and the results of such confusing situations (Mathews, 2005). For instance, the study revealed that, $16.0 \%$ of the pupils had poor relationship with parents or guardians and an overwhelming majority of the pupils that was $71.2 \%$ had a "fair" relationship with parents or guardians.

Teenagers rely on their friends for information as they want to be accepted within a particular social group. This information is often misleading and uninformed. They often get pregnant not to please themselves, but only to be accepted within a group of pregnant or parenting friends. Sometimes they advise each other that in order to keep a loved boyfriend the solution is to have sex with him and bear a child for him. That is often misguided and completely inaccurate (Halinan \& Williams, 1990).

Another factor worth exploring is the socioeconomic status of parents or guardians. The financial position of the family may also influence the behaviour of an individual. The socio-economic background of the family would either enhance or destroy the self-esteem of its members, particularly the teenagers. It was discovered that $44.8 \%$ of the pupils regarded their parents as "poor"; whereas $52.8 \%$, regarded them as "fairly poor" and $2.4 \%$ could not declare with certainty the socioeconomic status of their families. Poverty pushes teenage girls to lead certain lives which could endanger their lives in so many ways. The absence of basic needs for children may cause children to lose interest in school as well. Poverty is one socio-economic factor that is associated with increased rates of teenage pregnancy. UNFPA (2003) has emphasized that economically poor countries such as Niger and Bangladesh have far more teenage mothers compared with economically rich countries such as Switzerland and Japan.

Furthermore, it was established that media has influence on teenagers. For example, $96 \%$ of the respondents said that, the media had a greater impact on the rate of teenage pregnancy in the District under study, while only $4 \%$ of the respondents disagreed with that notion. Sex on television and movies involved people who do not display marital ties or good personal conduct. The actual consequences of sex such as unwanted pregnancies are not shown. Instead sex looks easy, funny and glamorous. It often appears as if everyone is doing it. Mass media production does not view morality as a priority instead immorality is used as a marketing strategy in advertisements, films, literature, music etc. Watching of pornographic and engaging in early sexual activity lead to pregnancy and school dropout among girls.

\section{Theme Four: The contents, quality and delivery methods of sex education curricula and impact on teenage pregnancy}

Education becomes the most important factor for empowering people. It provides knowledge and information which in turn bring about desirable changes in the way people think, feel and act. Education also builds a sense of self-esteem, self-confidence and the realization of person's potential.

All respondents (teachers) in the study said they did not have teaching resources to effectively teach sex education. It was discovered that sex education did not exist as a subject with a curriculum but rather some selected topics in integrated science and other subjects made it possible for teachers to teach sex related topics. Thus, on the scope of sex education all respondents' (100\%) indicated it was limited in substance or insufficient. Moreover, $32.1 \%$ of respondents indicated that special skills were needed to teach sex education as a subject in the schools. In addition, $67.9 \%$ of the respondents interviewed admitted that it was difficult to teach sex education as a subject. The reasons provided echoed lack of teaching and learning materials, lack of a curriculum to guide the teachers to effectively teach the subject. The study confirmed that Ghana Education Service as the 
professional body of education managing basic schools in the country did not have any accredited course known as Sex Education to be taught in the training colleges where basic school teachers are trained.

\section{CONCLUSION}

The study sought to investigate the impact of sex education on teenage pregnancy in the Bawku Municipal District of the Upper East Region of Ghana. The study was guided by four research questions, which focused on the prevalence and trend of teenage pregnancy in the District, participants' perceptions of teenage pregnancy and the implications, causes of teenage pregnancy and the content, quality and delivery methods of sex education curricula in Ghana. The background of the study, the problem statement and research questions informed the literature review for the study. The methodology gave details on the research design adopted for the study and data obtained from the field were analyzed and presented on the basis of the main research questions of the study.

The study discovered that Basic Schools in Ghana did not have sex education syllabus to teach the subject, but rather selected topics in integrated science, social studies, HIV/AIDs syllabus and occasional health talks created the awareness and provided knowledge for pupils in the basic schools in sex education. Teenage pregnancy in basic schools led to school dropout, unemployment, and single parenting. Teenage pregnancy was affirmed to be high in the study by $97.6 \%$ of the participants. Some of the causes mentioned include, peer pressure influence, low value of education, media influence, lack of parental support and poverty. The study concluded that, teenage pregnancy was a major problem in basic schools in the Bawku Municipal District of the Upper East Region of Ghana.

The recommendations stated below are not in any particular order, priority or preference. They are of equal importance to the researchers and participants of the study. Sex education should not be just a concept but should be developed further as a complete discipline for basic schools. It should not be treated as part of other learning areas but should rather enjoy autonomy with its own learning curriculum. That will expose learners to detailed firsthand information on sex related issues. It will enable learners to receive information in full and not in pieces in order to dissipate ill-informed advice through the media and peers.

Parents should talk openly and freely with their children about sex. If children get proper information and guidance from their parents at home they would disregard whatever misinformation they come across outside the boundaries of their homes. Parents should teach their young ones about their own sexuality, possible changes, implications and prevention or protection practices.

Each community should endeavour to put in place recreational facilities with extensive programmes for teenagers. Teenagers in some cases engage in sex due to the fact that they have nothing to do, so, if learners within the communities have sporting and cultural activities to keep them busy there would not be enough time to think about or engage in sex.

The creation of central venues such as clinics for the youth could help in the campaign for sex education awareness and that would minimize the influence from peer pressure. In such centres the awareness campaign on the effects of early sex, unsafe and unprotected sexual conduct could be discussed with teenagers.

The parent-teacher-associations in the District should be encouraged to ensure a constant interaction between parents and teachers in various schools and communities. This will enable teachers to discuss issues affecting children with their parents or guardians. Religious groups should be seriously involved in the crusade to teach children sex education. Their viewpoint that sex education for children was associated with encouraging immorality should be abolished.

The District Assembly and the District Education Directorate in collaboration with NGOs should endeavour to identify and support needy girls. Educational Endowment Funds should be established in order to raise funds to support needy girls. Such efforts may save the girls from the effect of poverty, which is one of the major causes of teenage pregnancies.

Ghana Education Service should establish counseling units in all basic schools in the District. The unit members should include teachers, parents, students, religious groups and opinion leaders in the communities. These teams should interact regularly with pupils to discuss issues related to peer pressure, truancy, sexuality and others. It is expected that if the 
above recommendations are adhered to it will go a long way to reduce teenage pregnancy and its consequence effect such as school dropout in the District.

\section{REFERENCES}

Ansah-Addo, H. (2005). Adolescent sex on the increase in Ghana: Behind the mask. Accra, Ghana. Retrieved from Ashesi.edu.gh.

Awoonor, W. (2010). Teenage pregnancy in Upper East alarming. Bolgatanga, Ghana: GNA.

Bawku Manucipal District (2017). Ghana districts: A repository of all local Assemblies in Ghana. Retrieved from http://www.ghanadistricts.com.

Boult, B. E. \& Cunningham, P. W. (1996). Black teenage pregnancy: An African perspective. International Journal of Adolescence and Youth, 3, 303-309.

GNA (May 10, 2013a) Ghana: 750,000 teenage pregnancies recorded annually. Ghana: Health News.

GNA (December 19, 2013b). Adolescent pregnancy in ascendency in Upper East Region. Accra, Ghana. Health News.

Halinan, M. T. \& Williams, R. A. (1990). Students' characteristics and the peer influence process. Sociology of Education, $63,122-132$.

Mathews, C. (2005). Reducing sexual risk behaviours: Theory research, successes and challenges. In S. S. Abdool-Karim and Q. Abdool-Karim (Eds.). HIV/AIDS in South Africa. Cambridge Univ. Press.

MoE (2013). Basic education sector improvement programme. Ghana: Policy Document, Ministry of Education.

Nakanyike, B. M., Kasente, D., \& Balihuta, A.M. (2002). Attendance patterns and causes of dropout in primary schools in Uganda. Kampala: Makerere University Institute of Social Research.

National Research Council (2001). Understanding dropouts: Statistics, strategies, and high-stakes testing. Washington, DC: National Acad. Press.

Osei, A. (2009). Sex education in Ghanaian society: The skeleton in the cupboard. Retrieved from Ashesi.edu.gh.

Owusu, S. A. (2012). Cultural and religious impediments against sex education. Accra, Ghana: GNA.

Secura, G. M., Madden, T., McNicholas, C., Mullersman, J., Buckel, C. M., Zhao, Q., \& Peipert, J. F. (2014). Provision of no-cost: Long-acting contraception and teenage pregnancy. New England Journal of Medicine, 371(14), 1316-1323. DOI: 10.1056/NEJMoa1400506.

Schwartz, P., \& Rutter, V. (1998). The gender of sexuality. London: Pine Forge Publishers.

Scottie, C.A., \& Awasu, C. (2011). Prevailing against the odds of dropping out of schools in Ghana. African Journal of Education and Technology, 1(2), 125-142.

UNFPA (2014). Operational guidance for comprehensive sexuality education: A focus on human rights and gender. New York.

UNICEF (2007a). Child poverty in perspective: An overview of child well-being in rich countries. Innocenti Report Card No. 7. Innocenti Research Centre, Florence.

UNICEF (2007b). Achieving universal primary education in Ghana by 2015: A reality or a dream? New York: UNICEF, Div. of Policy and Planning.

WHO (2014). Adolescent pregnancy. Retrieved from http://www.who.int/.

WIDE (2014). Global education monitoring report. UNESCO: Retrieved from www. education-inequalities.org.

Wikan, G. (n.d.). Non-enrolled, drop-outs and pupils: The state of education for all in Namibia. Retrieved from http://www.pef. uni-lj.si/978-961-6637-06-0/261-269.pdf.

World Bank (2005). Expanding opportunities and building competencies for young people: A new agenda for secondary education. Washington DC: World Bank. 